\title{
Fibrillation and characterization of lignin-containing neutral sulphite (NS) pulps rich in hemicelluloses and anionic charge
}

\author{
Saara Hanhikoski · Iina Solala $\cdot$ Panu Lahtinen · Klaus Niemelä • \\ Tapani Vuorinen
}

Received: 28 January 2020/ Accepted: 13 May 2020/Published online: 29 May 2020

(C) The Author(s) 2020

\begin{abstract}
The potential of neutral sulphite pulps from softwood with different yields (c. 58-84\%) and high residual lignin contents (c. 10-25 wt\%) was investigated as a raw material for lignin-containing cellulose nanofibrils (LCNFs) by following their fibrillation during grinding. It was found that the lower yield (58-65\%) pulps needed two grinding cycles to produce fibrillated fibers with water retention values (WRV) as high as $400 \mathrm{~g} / \mathrm{g}$ (at the energy consumption level of $1400 \mathrm{kWh} / \mathrm{t}$ ). In contrast, the high yield (77-84\%) pulps fibrillated more slowly, requiring five grinding cycles to reach comparable WRV values. Apparently, higher crosslinking degrees of lignin in the high yield pulps are hampering the fibrillation, although the high hemicellulose contents
\end{abstract}

Electronic supplementary material The online version of this article (https://doi.org/10.1007/s10570-020-03237-z) contains supplementary material, which is available to authorized users.

S. Hanhikoski $(\bowtie) \cdot$ P. Lahtinen · K. Niemelä

VTT Technical Research Centre of Finland Ltd,

P.O. Box 1000, FI-02044 VTT, Finland

e-mail: saara.hanhikoski@kemira.com

Present Address:

S. Hanhikoski

Kemira Oyj, P.O. Box 44, FI-02271 Espoo, Finland

I. Solala $\cdot$ T. Vuorinen

Department of Bioproducts and Biosystems, School of Chemical Engineering, Aalto University, P.O. Box 16300, FI-00076 Aalto, Finland
(21-24 wt\%) and the high charge densities (200-350 $\mu \mathrm{mol} / \mathrm{g}$, originating from carboxylic and sulphonic acid groups) of the pulps were expected to enhance the fibrillation. Nevertheless, regardless of the different fibrillation behaviour, most of the pulps formed $\mathrm{c}$. $10-15 \%$ of nanosized material below $30 \mathrm{~nm}$ and significant amounts of fibrils with size under $100 \mathrm{~nm}$ based on the centrifugation method and FE-SEM images. As the pulps were of moderate to high yield and fibrillated easily without any chemical or enzymatic pretreatments, they show promise for costefficient production of LCNFs. The nanopapers prepared from the fibrillated pulps showed tensile strengths (73-125 MPa) comparable with the nanopapers from high yield mechanical pulps, whereas the water contact angles $\left(41^{\circ}-58^{\circ}\right)$ were closer the those of chemical pulps.

Keywords Galactoglucomannan · Lignincontaining cellulose nanofibrils (LCNFs) -

Nanopaper · Softwood · Neutral sulphite pulp ·

Sulphonic acid group

\section{Introduction}

Cellulose nanofibrils (CNFs) have been one of the key research areas of cellulose chemistry for more than a decade, having notable potential in for example packaging, food and cosmetics applications. Despite 
the increasing production of CNFs at industrial scale, the high energy need for fibrillation remains one of the main challenges (Nechyporchuk et al. 2016). The energy consumption can be reduced significantly by chemical means, e.g. TEMPO (2,2,6,6-tetramethylpiperidine-1-oxyl radical)-mediated oxidation (Saito et al. 2006, 2007) and carboxymethylation (Wågberg et al. 2008), or by mild enzymatic hydrolysis of cellulose (Henriksson et al. 2007; Pääkkö et al. 2007). However, these techniques remain rather expensive for bulk industrial use due to the high cost of the required chemicals and enzymes (Solala et al. 2020). Presently, CNFs are most commonly produced from fully bleached chemical pulps. With the strong need of lowering the chemical and energy consumptions of CNF production, there has been a growing interest in employing alternative raw materials with higher yields, such as unbleached or partially bleached pulps and even wood sawdust (Spence et al. 2010a; Ferrer et al. 2012; Solala et al. 2012; Hoeger et al. 2014; Lahtinen et al. 2014; Rojo et al. 2015; Visanko et al. 2017; Yousefi et al. 2018; Ämmälä et al. 2019).

In addition to the efficient utilization of the wood raw material by maintaining the higher pulp yield, some of the unbleached or partially bleached pulps have been noted to fibrillate more readily than fully bleached pulps (Spence et al. 2010a, b; Ferrer et al. 2012; Lahtinen et al. 2014). It has become well-known that higher lignin and hemicellulose contents of the unbleached pulps enhance fibrillation, compared to the fully bleached pulps (Iwamoto et al. 2008; Ferrer et al. 2012; Solala et al. 2012; Tenhunen et al. 2014). However, the role of lignin content is not entirely straightforward as the impacts of lignin may also depend on its structure (Solala et al. 2020). On the one hand, lignin has frequently been suggested to promote fibrillation through a radical scavenging mechanism, decreasing the probability of reformation of the covalent bonds that get ruptured during the intense mechanical grinding (Dizhbite et al. 2004; Solala et al. 2012; Rojo et al. 2015). On the other hand, lignin can also hinder fibrillation, e.g. in the case of mechanical pulps (Spence et al. 2010a; Ferrer et al. 2012; Hoeger et al. 2013; Lahtinen et al. 2014), probably owing to the cross-linked structure and relatively high hydrophobicity of native lignin compared to carbohydrates (Figueiredo et al. 2018; Solala et al. 2020). In contrast to lignin, the effects of hemicelluloses seem to be better understood, since their water retention capacity and ability to prevent fibril coalescence upon drying of cellulosic materials are well-known (Iwamoto et al. 2008; Pönni et al. 2012; Chaker et al. 2013). These properties of hemicelluloses originate from electrostatic repulsion from carboxylic acid groups and steric repulsion caused by the side chains (Chaker et al. 2013; Tenhunen et al. 2014).

Sulphonation of lignin is a well-known method used to enhance fibre separation in chemi-mechanical and semi-chemical pulp production, but its ability to facilitate fibrillation of wood fibres has only recently been studied (Brodin and Eriksen 2015; Ämmälä et al. 2019). Sulphonation reduces lignin softening temperature, which increases the flexibility and deformability of the fibres (Östberg and Salmen 1988; Ölander et al. 1989). In addition to chemical modification, lignin can be softened thermally to enhance fibrillation, as shown by Visanko et al. (2017). Also, together with carboxylic acid groups, sulphonic acid groups create repulsive forces to loosen the fibril cohesion and increase the swelling of the cell wall, thus facilitating fibrillation.

Generally, CNFs dispersed in an aqueous medium form a highly viscous suspension at very low concentrations (c. <2\%) (Solala et al. 2020) having tendency to aggregate at higher concentrations. This may cause challenges in processing, storing and transportation of CNFs. In general, efficient water removal is important e.g. for the production of packaging materials, composites, films and barriers, whereas high water retention may be beneficial in applications such as rheology modifiers, hydrogels, and absorbent materials (Nechyporchuk et al. 2016; Solala et al. 2020). Fibrillation increases the accessibility of hydroxyl and anionic groups to water resulting in high swelling and water retention capacity, which also affects the dewatering of the CNF suspension (Fält et al. 2003; Dimic-Misic et al. 2013; Rantanen et al. 2015). In contrast to carbohydrates, lignin is typically more hydrophobic and may decrease the water absorption capacity of lignin-containing CNFs (LCNFs). However, the hygroscopicity of LCNFs can be controlled not only by the amount of lignin and carbohydrates, especially hemicelluloses, but also by introducing hydrophilic groups into the lignin structure, which depend on the pulping method selected (Solala et al. 2020). The presence of sulphonated lignin in LCNFs would be expected to increase the hydrophilicity, as reported by Ämmälä et al. (2019) for fibrillated wood sawdust. 
However, LCNFs produced from the chemical $\mathrm{SO}_{2}-$ ethanol-water pulps (Rojo et al. 2015) have been reported to be easy to dewater, despite significant lignin sulphonation. This suggests that the role of hemicelluloses and the overall chemical composition of the LCNFs are significant for the dewatering behaviour.

In this study, a new potential family of raw materials, semi-chemical pulps produced by neutral sulphite (NS) pulping, is introduced for LCNF production. These types of pulps possess the main aforementioned key elements expected to enhance fibrillation: high residual lignin and hemicellulose contents and a relatively high charge density (Hanhikoski et al. 2016, 2019). Furthermore, due to the high pulp yield and by excluding bleaching and other chemical treatments before fibrillation, these pulps may be considered as cost-efficient raw materials compared to the fully bleached chemical pulps with lower yields. In this study, six NS pulps from softwood with different yields and lignin contents were used to follow their fibrillation during grinding as a function of the specific energy consumption. In addition, nanopapers were prepared from the fibrillated pulps and their mechanical and water interaction properties were analysed.

\section{Materials and methods}

Materials

Six different NS pulps selected for this study were produced from Scots pine (Pinus sylvestris L.) chips as described by Hanhikoski et al. (2019). Changing the reaction time (from 5 to $240 \mathrm{~min}$ at $180{ }^{\circ} \mathrm{C}$ ) and the addition of anthraquinone (AQ) as a catalyst (0 vs. $0.1 \%$ on o.d. wood), pulps with different yields and chemical compositions were produced (Table 1). Otherwise, the pulping conditions were uniform. The pulps included two neutral sulphite (NS) and four neutral sulphite anthraquinone (NSAQ) pulps, the following codes referring to the total pulp yield (Table 1). All chemicals used for the experiments and analyses were of analytical grade.
Characteristics of pulps

The total pulp yield was measured gravimetrically. The carbohydrate compositions, and the contents of lignin and extractives were determined for the initial wood material and the pulps as described by Hanhikoski et al. (2016). The carbohydrates and lignin contents were analysed in triplicates with standard deviations below 2\%. The carbohydrate results (Table 1) were converted into polysaccharide forms according to Janson (1970). The total amount of acidic groups was determined from the pulps by conductometric titration according to the SCAN-CM 65:02 standard method. The contents of sulphonic acid groups were estimated separately from the titration results. The samples were analysed in duplicates.

\section{Production of LCNFs}

Never-dried pulps were washed into sodium form to assure comparable $\mathrm{pH}$, ionic strength and counter ion type in all samples (Swerin et al. 1990; Lahtinen et al. 2014) prior to fibrillation by a MKZA10-15J Supermasscolloider friction grinder (Masuko Sangyo Co, Kawaguchi City, Japan) in accordance with Lahtinen et al. (2014). Briefly, the pulps were diluted into $2 \%$ consistency, soaked for 10-15 min, and dispersed at $2000 \mathrm{rpm}$ for $10 \mathrm{~min}$ before grinding. The pulps were cycled altogether five times through the grinder, and the samples were taken after the second, third and fifth cycles at the constant energy consumption levels (approximately 1, 3 and $13 \mathrm{kWh} / \mathrm{kg}$ ) for further analysis. For the first two cycles, the grinding stone was a standard stone type MKE10-46 made of silicon carbide. In the following cycles, the fine stone type MKGA10-80 made of aluminium oxide and resins was used. The used rotation speed was $1500 \mathrm{rpm}$ (except $1700 \mathrm{rpm}$ for the final cycle of the pulp NSAQ-58). The energy consumption of fibrillation was monitored with a frequency converter connected to the grinder.

\section{Characterization of LCNFs}

The extent of fibrillation of the NS(AQ) pulps was followed by analysing samples after the second, third, and fifth grinding cycles. Water retention values (WRV) were measured by a modified procedure of ÅAGWR method (Sandas et al. 1989), described in 
Table 1 The applied NS(AQ) pulping conditions and the resulting total pulp yields, chemical compositions and anionic charges

\begin{tabular}{|c|c|c|c|c|c|c|c|}
\hline Sample & Scots pine & NSAQ-84 & NSAQ-77 & NSAQ-64 & NSAQ-58 & NS-78 & NS-65 \\
\hline Temperature $\left({ }^{\circ} \mathrm{C}\right)$ & & 180 & 180 & 180 & 180 & 180 & 180 \\
\hline Time at $180{ }^{\circ} \mathrm{C}(\mathrm{min})$ & & 5 & 30 & 120 & 240 & 60 & 240 \\
\hline $\mathrm{AQ}\left(\%^{\mathrm{a}}\right)$ & & 0.1 & 0.1 & 0.1 & 0.1 & - & - \\
\hline Total pulp yield $\left(\%^{\mathrm{a}}\right)$ & & 84.0 & 77.5 & 64.4 & 57.7 & 78.3 & 65.0 \\
\hline \multicolumn{8}{|l|}{ Chemical composition (wt $\%$ ) } \\
\hline Cellulose & 40.6 & 47.5 & 50.9 & 60.4 & 66.9 & 49.3 & 59.0 \\
\hline Galactoglucomannan & 15.2 & 14.8 & 15.0 & 16.7 & 15.0 & 13.7 & 13.8 \\
\hline Arabinoxylan & 8.3 & 9.5 & 9.2 & 8.6 & 7.8 & 8.6 & 7.6 \\
\hline Total lignin & 27.5 & 23.4 & 20.1 & 14.0 & 9.9 & 24.0 & 19.3 \\
\hline Extractives & 3.2 & 0.4 & 0.6 & 0.3 & 0.3 & 0.5 & 0.3 \\
\hline Others $^{\mathrm{b}}$ & 5.1 & 4.4 & 4.1 & - & - & 3.8 & - \\
\hline Total anionic groups $(\mu \mathrm{mol} / \mathrm{g})$ & & $327 \pm 2$ & $263 \pm 10$ & $220 \pm 7$ & $205 \pm 9$ & $347 \pm 4$ & $320 \pm 4$ \\
\hline Sulphonic acid groups $(\mu \mathrm{mol} / \mathrm{g})$ & & $210 \pm 3$ & $181 \pm 12$ & $140 \pm 6$ & $120 \pm 11$ & $236 \pm 3$ & $214 \pm 8$ \\
\hline
\end{tabular}

${ }^{\mathrm{a} O n}$ o.d. wood

${ }^{b}$ E.g. inorganics and other carbohydrates to complete the balance

detail by Lahtinen et al. (2014). Briefly, the modified WRV measurements differ from the traditional SCAN-C 62:00 method in that they utilize $30 \mathrm{~s}$ pressure filtration at 0.5 bar instead of $15 \mathrm{~min}$ centrifugation at $3000 \mathrm{~g}$. At least three parallel measurements were executed for each ground sample and the original pulp samples. The apparent viscosities were measured as an indirect method to evaluate the extent of fibrillation. The measurements were done with a Brookfield rheometer RVDV-III as described by Lahtinen et al. (2014). Before analysis, the samples were diluted to $1.5 \%$ consistency, mixed with UltraTurrax disperser (IKA) for $2 \mathrm{~min}$, and were let to stand for $30 \mathrm{~min}$. Each sample was measured in duplicate. The yield of nanosized material was determined gravimetrically according to Ahola et al. (2008) after the second and fifth grinding cycles. The fibril suspension was diluted to $1.7 \mathrm{~g} / \mathrm{L}$, dispersed for 10 min, and finally ultracentrifuged at $10,000 \mathrm{~g}$ for $2 \mathrm{~h}$. The amount of nanosized material was calculated as the solid content of the supernatant in relation to the solid content of the whole sample. The samples were analysed in duplicate (except the NSAQ-84 pulp after second cycle). The numerical values and standard deviations for the results of WRV, apparent viscosity and yield of nanosized material are presented in the supplementary material (Table S1). To study the morphology of LCNFs and to obtain an overall view of the fibril dimensions, field emission scanning electron microscope (FE-SEM) images were taken from the final fibrillated samples. For the FE-SEM imaging the samples were coated with platinum, and a Zeiss Merlin FE-SEM device (ZEISS, German) was used at an accelerating voltage of $1.0 \mathrm{kV}$. To complement the results and to visualize the changes in fibres, the number of residual fibres measured by Kajaani Fiberlab analyser (Metso Automation, Finland) and optical microscopy images were also obtained. The results are presented in the supplementary material (Table S1, Figs. S1 and S2). For the Fiberlab measurements, the samples were diluted with water to $40 \mathrm{mg} / \mathrm{L}$ consistency with an impeller for $10 \mathrm{~min}$. The dispersed samples of $50 \mathrm{~mL}(\sim 2 \mathrm{mg}$ in dry weight) were fed into the analyser, and two parallel measurements were carried out for each sample. The optical microscopy (Olympus BX 61 microscope equipped with a ColorView 12 camera) images were taken from the samples after the second and the fifth cycle in the grinder. The samples were first dyed with $1 \%$ Congo red solution and further diluted with water for the microscope plate.

Preparation and characterization of LCNF nanopapers

The LCNF nanopapers were prepared from the final fibrillated samples by slightly modifying the method of Österberg et al. (2013). A 300-mL volume of $0.2 \%$ 
LCNF suspension was pressure filtrated over a Sefar Nitex polyamine monofilament open mesh fabric with a $10 \mu \mathrm{m}$ pore size at 2.5 bar pressure. After $\sim 2 \mathrm{~h}$ filtration, the wet films were rolled ten times between two membrane filters and two blotting papers with a smooth metal rolling pin for further consolidating the structure. Finally, the nanopapers were dried between clean blotting papers under load $(1.8 \mathrm{kPa})$ and heat $(80$ ${ }^{\circ} \mathrm{C}$ ) for $2 \mathrm{~h}$. This yielded $137 \mathrm{~cm}^{2}$ nanopapers with basis weights of $56 \pm 5 \mathrm{~g} / \mathrm{m}^{2}$ and apparent densities of $920 \pm 20 \mathrm{~kg} / \mathrm{m}^{3}$.

Mechanical properties of the nanopapers were determined using a modified SCAN-P 38:80 standard method. The measurements were carried out using a Lloyd LS5 (Lloyd Instruments Ltd., Bognor Regis, UK) tensile testing apparatus equipped with a $1 \mathrm{kN}$ load cell using testing speed of $10 \mathrm{~mm} / \mathrm{min}$. The width of the tested nanopaper samples was $15 \mathrm{~mm}$ and the grip distance was $40 \mathrm{~mm}$. The nanopapers were conditioned at $23{ }^{\circ} \mathrm{C}$ and $50 \% \mathrm{RH}$ at least $24 \mathrm{~h}$ before the testing. The average and standard deviation of five measurements (except four measurement in the case of NSAQ-84 and NSAQ-58) are reported. In addition, the water contact angles of the nanopapers were measured using Theta Optical Tensiometer (Biolin Scientific, Sweden). Three measurements per sample were carried out at $23{ }^{\circ} \mathrm{C}$ and $50 \% \mathrm{RH}$.

\section{Results and discussion}

\section{Characteristics of pulps}

The yields of the NS(AQ) pulps (57.7-84.0\%) (Table 1) represent intermediates between typical chemical (45-55\%) and high yield mechanical (>90\%) pulps. Consequently, the total lignin contents of the pulps were still rather high, in the range of 9.9-24.0 wt $\%$. Additionally, the heptane-soluble extractives contents were $0.3-0.6 \mathrm{wt} \%$, decreasing slightly as the pulp yield decreased. In most studies, LCNFs have previously been produced either from unbleached chemical pulps (e.g. kraft pulp) with lignin contents up to $14 \mathrm{wt} \%$ (Spence et al. 2010a, b; Ferrer et al. 2012; Lahtinen et al. 2014) or from mechanical pulps (e.g. CTMP and TMP) with lignin contents over 20 wt\% (Lahtinen et al. 2014; Visanko et al. 2017; Herrera et al. 2018). However, the comparison of fibrillation of different pulps based solely on their lignin content should be done with caution since the raw material sources and the selected pulping methods may not only affect the content of lignin but also its chemical structure. For example, in the NS(AQ) pulps (Hanhikoski et al. 2016) and SEW ( $\mathrm{SO}_{2}$-ethanolwater) pulps (Rojo et al. 2015), sulphonic acid groups formed during pulping remain partially in the residual lignin, thus increasing its hydrophilicity and swelling ability (Ämmälä et al. 2019).

Another notable characteristic of the NS(AQ) pulps is their high galactoglucomannan (13.7-16.7 wt\%) and arabinoxylan (7.6-9.5 wt\%) contents (Table 1), compared to the unbleached and bleached kraft pulps typically used for the CNF production. Of the hemicelluloses, especially galactoglucomannan (GGM) is known to considerably enhance fibrillation (Iwamoto et al. 2008; Morais de Carvalho et al. 2019). It is evident that over $55 \%$ and $70 \%$ of the original GGM in wood remained in the intermediate (58-65\%) and the high yield (77-84\%) NS(AQ) pulps, respectively (Hanhikoski et al. 2019). Their high yield is caused by deacetylation of GGM followed by its stabilization under the applied neutral sulphite pulping conditions (Annergren and Rydholm 1959, 1960). For comparison, over $70 \%$ of GGM is degraded or dissolved in the alkaline kraft pulping process (Sjöström 1977; Paananen et al. 2013).

The electrical charge densities of the NS(AQ) pulps (Table 1) were comparable to those of carboxymethylated bleached pulps, ranging from 200 to $350 \mu \mathrm{mol} / \mathrm{g}$ (Horvath et al. 2006; Fall et al. 2011; Junka et al. 2013). Out of these 120-240 $\mu \mathrm{mol} / \mathrm{g}$ were strong sulphonic acid groups-the rest were carboxylic acid groups bound mainly in hemicelluloses (Sjöström 1989). The total anionic groups and the sulphonic acid groups both showed a linear correlation with residual lignin, displaying $\mathrm{R}^{2}$ values of 0.85 for the total anionic groups and 0.89 for the sulphonic acid groups (Fig. 1). To compare, the charge densities of unbleached kraft pulps are typically in the range of 70-200 $\mu \mathrm{mol} / \mathrm{g}$ (Lindgren et al. 1994; Fardim et al. 2002; Bhardwaj et al. 2004), and those of CTMP about 120-190 $\mu \mathrm{mol} / \mathrm{g}$ (Zhang et al. 1994; Fardim et al. 2002; Lahtinen et al. 2014). Since the fibrillation has not been found to have any noticeable effect on the total charge of cellulosic fibres (Bhardwaj et al. 2004; Junka et al. 2013), it was assumed that the charges present in the NS(AQ) pulps are mostly preserved in the resulting LCNFs. 


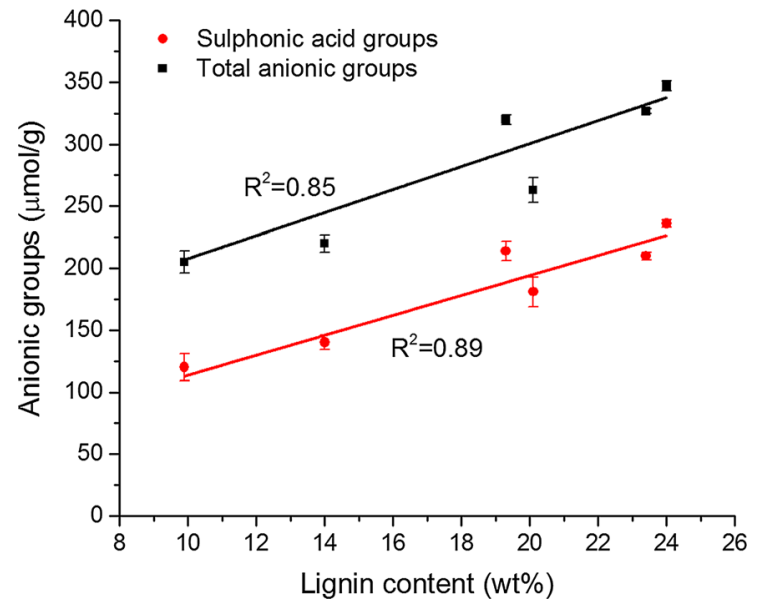

Fig. 1 Total anionic and sulphonic acid group contents ( $\mu \mathrm{mol} /$ $\mathrm{g}$ ) as a function of residual lignin content (wt\%) for the NS(AQ) pulps

Mechanical refining has often been carried out (Spence et al. 2010a; Ferrer et al. 2012; Rojo et al. 2015) as a pretreatment before the final fibrillation of the fibres. However, the NS(AQ) pulps were now only gently disintegrated with two cycles in a disk refiner to separate the fibres from the chip matrix (Hanhikoski et al. 2019). Therefore, the pulps for fibrillation were coarse and heterogeneous, especially in the case of the highest yield pulps. According to Spence et al. (2011), producing CNFs by grinding does not require refining as a pretreatment, contrary to microfluidization. Thus, in this study, regardless of the heterogeneity, relatively high yields and lignin contents of the NS(AQ) pulps, the high hemicellulose contents and charge densities were expected to assure effective fibrillation of these pulps in a grinder.

Extent of fibrillation

The fibrillation of the pulps was followed by analysing water retention value (WRV), apparent viscosity, and the content of residual fibres (supplementary material) after the second, third and fifth grinding cycles. Based on the results, the studied lower and higher yield NS(AQ) pulps had different fibrillation behaviours. The lower yield pulps (NSAQ-64, NSAQ-58 and NS65) showed high fibrillation ability in the early stage of grinding, whereas the higher yield pulps (NSAQ-84, NSAQ-77, and NS-78) needed more grinding cycles to get fibrillated. After five cycles of grinding, all of the pulps were fibrillated into gel-like suspensions.

Fibrillation of the fibre structure increased the WRV, as could be expected with the enhanced accessibility of hydroxyl, sulphonic and carboxylic acid groups to surrounding water. The lower yield pulps (NSAQ-64, NSAQ-58 and NS-65) displayed very high WRVs, almost $400 \mathrm{~g} / \mathrm{g}$, even at the lowest specific energy consumption levels (Fig. 2). This indicated that extensive fibrillation and swelling readily took place during the first two grinding cycles. For comparison, to reach the WRV level of $400 \mathrm{~g} / \mathrm{g}$, the lower yield NS(AQ) pulps needed around $1 \mathrm{kWh} /$ $\mathrm{kg}$ less energy compared to unbleached softwood kraft pulp with lignin content $2.6 \mathrm{wt} \%$ (1.4 and $2.5 \mathrm{kWh} / \mathrm{kg}$, respectively) (Lahtinen et al. 2014). In contrast, for the higher yield pulps (NSAQ-84, NSAQ-77, and NS-78) it took about $12 \mathrm{kWh} / \mathrm{kg}$ to reach comparable WRV values, which would indicate less effective fibrillation of these pulps. It is interesting to note that the pulps NSAQ-77 and NS-65 with comparable lignin contents (20.1 and $19.3 \mathrm{wt} \%$ respectively) showed very different fibrillation behaviour. This may be explained by the higher anionic charge of the NS-65 pulp, although no clear correlation between the anionic charges and WRVs could be found.

Rheological properties of the pulps, measured as apparent viscosity, are another way to study the degree of fibrillation. The apparent viscosity increased as a function of energy consumption being higher for the lower yield pulps (NSAQ-64, NSAQ-58 and NS-65)

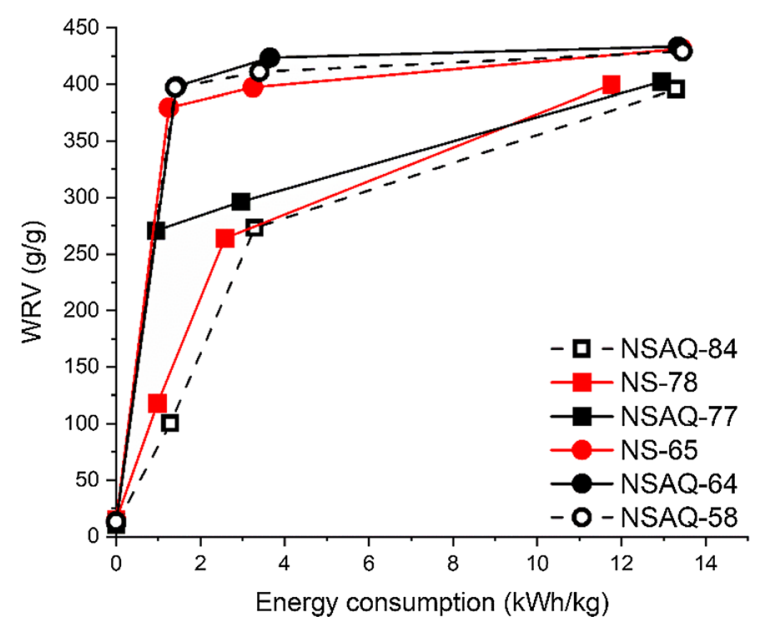

Fig. 2 The water retention values (g/g) of the NS(AQ) pulps as a function of specific energy consumption $(\mathrm{kWh} / \mathrm{kg})$ 
compared to the higher yield pulps (NSAQ-84, NSAQ-77, and NS-78) (Fig. 3), well in line with the WRV results. It is noticeable that the apparent viscosity of NSAQ-84, NSAQ-77, and NS-78 pulps starts to increase only after the third grinding cycle, which may indicate that the major part of the fibrillation proceeds only later towards the end of grinding for these pulps. The apparent viscosities of the lower yield pulps (NSAQ-64, NSAQ-58 and NS65) were comparable with unbleached kraft pulp but clearly higher than the values reported for bleached kraft pulp (Lahtinen et al. 2014). The high apparent viscosities may indicate challenges in handling of the material in industrial processes, e.g. in mixing and pumping.

In order to estimate the fibril dimensions and the overall extent of fibrillation, the yields of nanosized material were determined after the second and fifth grinding cycles (Fig. 4) and FE-SEM images were studied after the final stage of grinding (Fig. 5). The nanosized materials separated by ultracentrifugation contain fibrils and fibril bundles with width up to ca. 20-30 nm (Pääkkö et al. 2007; Wågberg et al. 2008; Besbes et al. 2011). After the second grinding cycle, more nanosized material was formed from the pulps with the lowest lignin contents (NSAQ-64 and NSAQ58) compared to the other pulps. Surprisingly, the yield of nanosized material formed in the pulp NS-65 was lower than could be expected based on other analyses, such as the WRV (Fig. 2) and the apparent

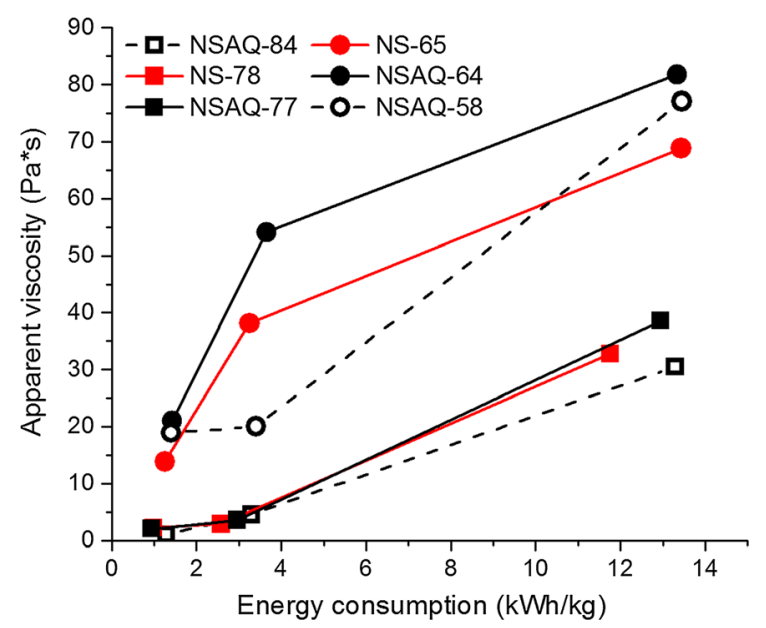

Fig. 3 The development of the apparent viscosities of the NS(AQ) pulps as a function of the specific energy consumption $(\mathrm{kWh} / \mathrm{kg})$

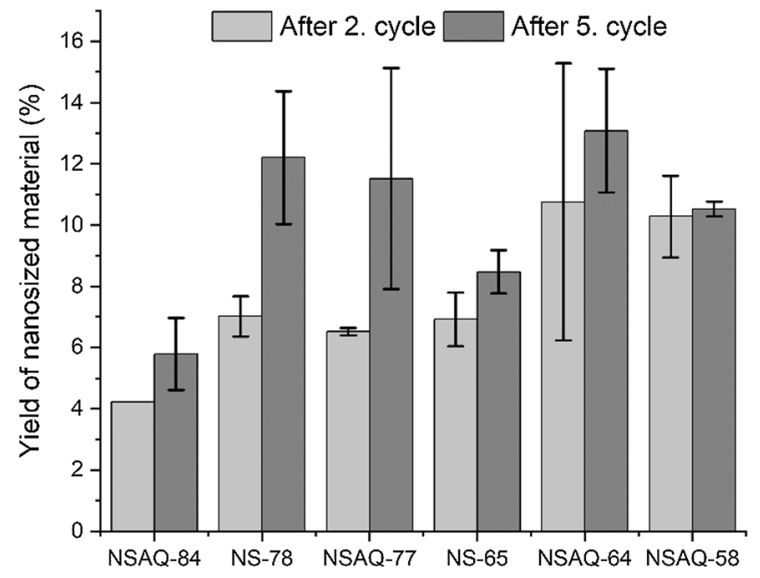

Fig. 4 The yields of nanosized material (\%) of the NS(AQ) pulps after the second and fifth grinding cycles

viscosity (Fig. 3). This may be explained by the inaccuracy of the relatively sensitive analysing method or by the formation of significant amount of nanosized material larger than $20-30 \mathrm{~nm}$ resulting in the comparable fibrillation performance with the NSAQ-64 and NSAQ-58 pulps. After the fifth grinding cycle, the differences in the results between all of the pulps seemed to even out, although the nanosized material in the highest yield pulp NSAQ-84 remained somewhat low. Altogether, at the energy consumption level of around $14 \mathrm{kWh} / \mathrm{kg}$, the NS(AQ) pulps gave nanosized material at a yield of ca. $10-15 \%$, which is more comparable with unbleached lignin-containing chemical pulps than mechanical pulps (Lahtinen et al. 2014).

Representative FE-SEM micrographs of the NSAQ-84 and NSAQ-58 LCNFs are shown in Fig. 5. In general, the LCNFs with the highest residual lignin contents (NSAQ-84, NSAQ-77, and NS-78) contained more fibre-like, partially fibrillated structures and fibril bundles. Based on the fibrillation results, it seems that the fibrillation behaviour of the NS(AQ) pulps was altered at the residual lignin content of around $19 \mathrm{wt} \%$, below which the pulps fibrillated more readily into LCNFs. Some residual fibre material was present also in the lowest lignin content samples (NSAQ-64, NSAQ-58 and NS-65), albeit to a lesser extent. This finding was supported by the Kajaani Fiberlab analyses and optical microscopy images presented in the electronic supplementary material (Table S1, Fig. S1 and S2) that showed a lower residual fibre content for the samples with a 
Fig. 5 FE-SEM images of the highest-yield NSAQ-84 pulp (a and b) and the lowest yield NSAQ-58 pulp (c and d) after the fifth cycle in the Masuko grinder
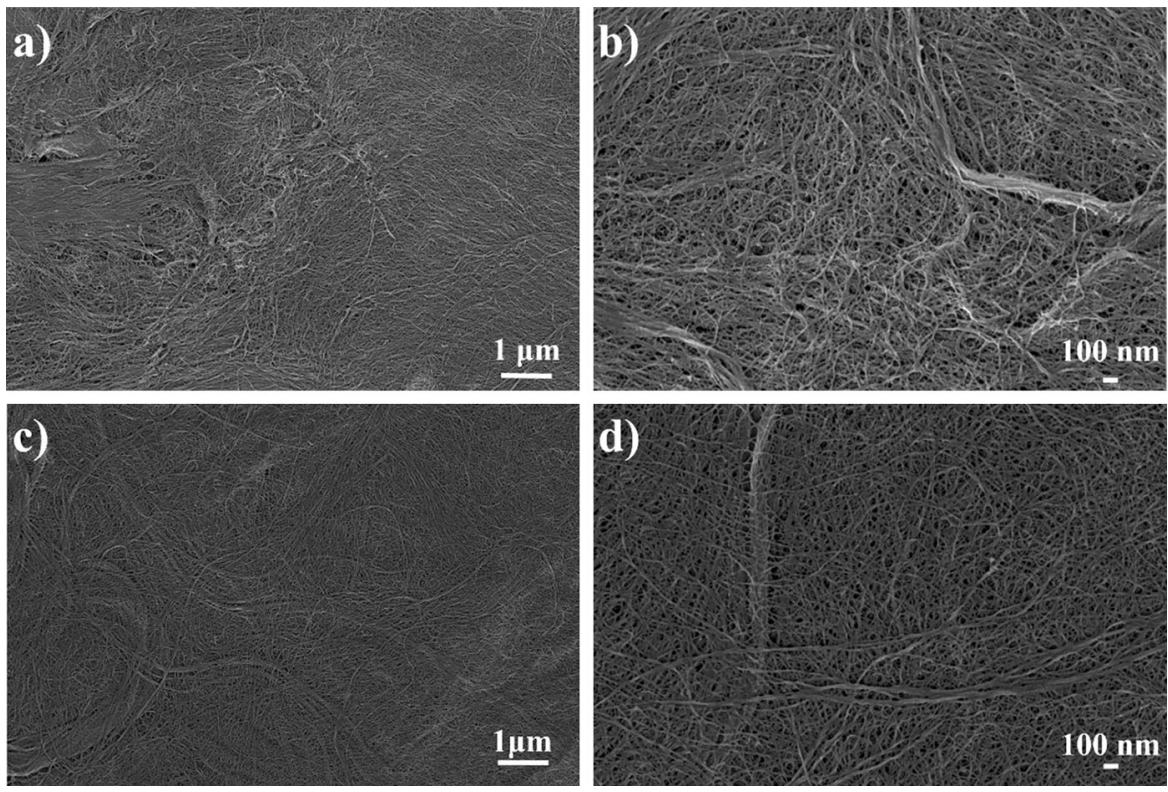

lower lignin content. Yet, it is apparent from the FESEM images that even the high-lignin pulps contained a significant portion of fibrils that had widths in the nano-range $(<100 \mathrm{~nm})$, indicating that the NS(AQ) pulps of different chemical compositions can be fibrillated to LCNFs.

\section{LCNF nanopaper properties}

The LCNF nanopapers were prepared from the fibrillated pulps after the fifth grinding cycle and tested for mechanical properties (Table 2; Fig. 6) and water contact angle (WCA) (Table 2; Fig. 7). An increase in lignin content up to $14 \%$ has previously been reported to improve the strength properties of LCNF nanopapers or films compared to fully bleached pulps (Spence et al. 2010a; Ferrer et al. 2012). This has

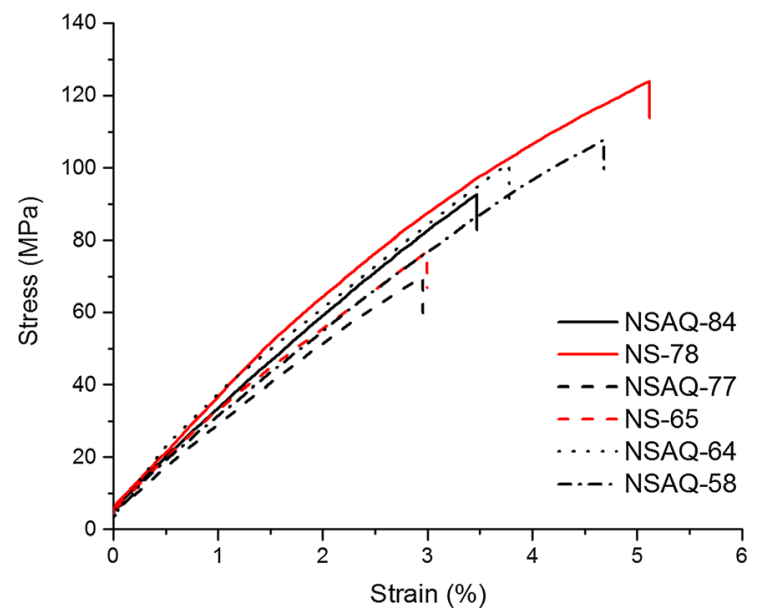

Fig. 6 The average stress-strain curves of the NS(AQ) LCNF nanopapers

Table 2 The mechanical properties and the water contact angles of the nanopapers prepared from the LCNF samples after the fifth grinding cycle

\begin{tabular}{lcccccc}
\hline Sample & NSAQ-84 & NSAQ-77 & NSAQ-64 & NSAQ-58 & NS-78 & NS-65 \\
\hline Thickness $(\mu \mathrm{m})$ & $62 \pm 3$ & $63 \pm 2$ & $63 \pm 1$ & $58 \pm 4$ & $50 \pm 5$ & $63 \pm 2$ \\
Tensile strength (MPa) & $94 \pm 13$ & $71 \pm 14$ & $102 \pm 10$ & $109 \pm 22$ & $125 \pm 11$ & $73 \pm 13$ \\
Young's modulus (GPa) & $4 \pm 1$ & $3 \pm 1$ & $5 \pm 1$ & $5 \pm 2$ & $4 \pm 1$ & $4 \pm 1$ \\
Strain at break (\%) & $4 \pm 2$ & $3 \pm 1$ & $4 \pm 1$ & $5 \pm 2$ & $5 \pm 2$ & $3 \pm 1$ \\
Water contact angle $\left({ }^{\circ}\right)$ & $58 \pm 1$ & $56 \pm 5$ & $41 \pm 0$ & $45 \pm 1$ & $52 \pm 2$ & $53 \pm 5$ \\
\hline
\end{tabular}




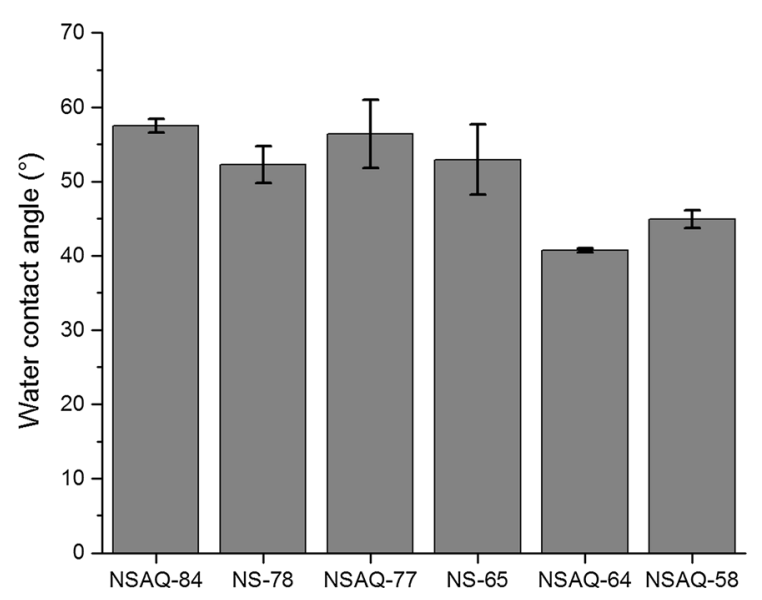

Fig. 7 Water contact angles $\left(^{\circ}\right)$ of the NS(AQ) nanopapers

been explained by the role of hemicelluloses in enhancing fibril-fibril bonding and the smaller fibril diameter and larger surface area of the LCNFs, which compacts the structure during nanopaper preparation (Spence et al. 2010a; Ferrer et al. 2012; Rojo et al. 2015). However, no clear correlation was now found between lignin content and strength properties of the nanopapers from the fibrillated NS(AQ) LCNFs. The nanopapers from the fibrillated NS-78, NSAQ-64, and NSAQ-58 pulps had the highest tensile strengths, over $100 \mathrm{MPa}$, although the pulps represented the highest $(24.0 \mathrm{wt} \%)$ and the lowest (14.0 and $9.9 \mathrm{wt} \%)$ lignin contents of the tested pulps. In addition, the Young's modulus and strain at break were slightly higher in these nanopapers, approximately 4-5 GPa and 4-5\%, respectively, compared to the nanopapers from other fibrillated pulps. Otherwise, the tensile strengths of the relatively high lignin content nanopapers (NSAQ-84, NSAQ-77, NS-65) remained between 71 and $94 \mathrm{MPa}$, and the average Young's modulus and strain at break were below $4 \mathrm{GPa}$ and $3.5 \%$ respectively.

The nanopapers from NS-78, NSAQ-64, and NSAQ-58 LCNFs showed comparable tensile strengths but lower Young's modulus compared to the values reported for the nanopapers from CNFs (Rojo et al. 2015) and cellulose microfibrils (Ämmälä et al. 2019) containing sulphonated lignin. In the case of NSAQ-84, NSAQ-77, NS-65, the tensile and strain values are close to those published for the nanopapers produced from high yield mechanical pulps (with lignin contents closer to the value of native wood) but again lower stiffness values were observed (Visanko et al. 2017). The preparation conditions of lignincontaining CNF nanopapers, especially the drying temperature and pressure, affect their structure and properties (Rojo et al. 2015; Visanko et al. 2017; Herrera et al. 2018). Generally, high lignin content prevents bonding between hydroxyl groups of cellulose and thus may hinder the strength of nanopapers. However, at elevated temperatures, lignin is plasticized and its $\mathrm{Tg}$ is decreased, consequently densifying the nanopaper structure and acting as an adhesive between fibrils (Abe et al. 2009; Ferrer et al. 2012; Rojo et al. 2015). For example, an increase in the drying temperature from 75 to $150{ }^{\circ} \mathrm{C}$ improved the tensile strength from 79.0 to $103.4 \mathrm{MPa}$, Young's modulus from 5.1 to $6.2 \mathrm{GPa}$, and strain at break from 2.7-3.5\% for nanopapers prepared from spruce groundwood NFs with lignin content of $27.4 \mathrm{wt} \%$ (Visanko et al. 2017).

Two groups of LCNF nanopapers with different paper surface wettabilities could be distinguished based on the WCA measurements (Table 2; Fig. 7). The WCA values from $52^{\circ}$ to $58^{\circ}$ demonstrated that the high lignin content nanopapers (NSAQ-84, NS-78, NSAQ-77, NS-65) had more hydrophobic surfaces than those containing less lignin (NSAQ-64, NSAQ58), showing the WCA values from $41^{\circ}$ to $45^{\circ}$ (Table 2). A similar trend of increasing WCA with higher lignin content has been observed earlier (Spence et al. 2010b; Rojo et al. 2015), although the linear correlation of the present results was rather moderate $\left(\mathrm{R}^{2}\right.$ value 0.66$)$. Interestingly, the WCA values of $\mathrm{NS}(\mathrm{AQ})$ nanopapers were much lower compared to the other high lignin-containing ( $>14$ $\mathrm{wt} \%$ ) nanopapers, which generally have shown WCA values of $\geq 70^{\circ}$ (Spence et al. 2010b; Ferrer et al. 2012; Rojo et al. 2015; Visanko et al. 2017; Herrera et al. 2018). Overall, our WCA values were close to those previously reported for nanopapers or films prepared from fibrillated chemical pulps with lignin contents below 5 wt\% (Spence et al. 2010b; Ferrer et al. 2012; Rojo et al. 2015). Thus, it can now be presumed that the relatively high hemicellulose content as well as sulphonated residual lignin considerably increased the hydrophilicity of the nanopapers. Considering both the WCA and WRV results, the NS(AQ) pulps may possess water retention and interaction characteristics that may be desirable depending on the intended end use. 


\section{Conclusions}

Neutral sulphite (NS(AQ)) pulps rich in hemicelluloses and anionic groups were demonstrated to be potential lignin-containing raw material for $\mathrm{CNF}$ production without any chemical or enzymatic pretreatment, and thus they may offer a cost-effective production route for LCNFs. The pulps with lower yields (58-65\% on o.d. wood) and moderate lignin contents (9.9-19.3 wt\%) fibrillated readily into LCNFs with high water retention capacity at the energy consumption level of $1400 \mathrm{kWh} / \mathrm{t}$. In contrast, the pulps with higher yields (77-84\% on o.d. wood) and lignin contents up to $24 \mathrm{wt} \%$ required more energy, approximately $12,000 \mathrm{kWh} / \mathrm{t}$, to reach comparable WRV values. The gradual breaking of the three-dimensionally cross-linked lignin network during pulping, accompanied by lignin sulphonation, likely causes the observed differences in fibrillation behaviour. After the lignin network has been disintegrated sufficiently, the presence of hemicelluloses and anionic groups allow the fibres to swell extensively, enhancing fibrillation. The lignin content, below which a rapid increase in fibre swelling ability was seen, occurred at the residual lignin content of around $19 \mathrm{wt} \%$ for the studied NS(AQ) pulps. Interestingly, the yield of nanosized ( $\sim 20-30 \mathrm{~nm}$ in width) material formed during fibrillation seemed to be relatively independent of the fibrillation behaviour of the pulps being approximately c. $10-15 \%$ in most of the NS(AQ) LCNFs.

The nanopapers prepared from NS(AQ) LCNFs showed tensile properties comparable with the LCNFs from high yield mechanical pulps. No clear trend between the mechanical properties of the nanopapers and fibrillation behaviour or lignin content of these pulps could be found. Interestingly, the WCA values measured from the NS(AQ) LCNF nanopapers indicated comparable hydrophilicity with the nanopapers prepared from the chemical pulps with significantly lower lignin contents $(<5 \mathrm{wt} \%)$. Thus, based on the WCA and WRV results, the NS(AQ) pulps may have interesting characteristics for applications requiring tuneable hydrophilicity and water interactions.

Acknowledgments Open access funding provided by Technical Research Centre of Finland (VTT). Financial support for this research from Academy of Finland (Grant Number 270756) and The Finnish Foundation for Technology Promotion is highly acknowledged. Katja Pettersson, Ulla
Salonen, Vuokko Liukkonen, Mari Leino, Jari Leino, and Asko Sneck are thanked for their skillful assistance in the experimental work, and Hannes Orelma for valuable discussions.

Open Access This article is licensed under a Creative Commons Attribution 4.0 International License, which permits use, sharing, adaptation, distribution and reproduction in any medium or format, as long as you give appropriate credit to the original author(s) and the source, provide a link to the Creative Commons licence, and indicate if changes were made. The images or other third party material in this article are included in the article's Creative Commons licence, unless indicated otherwise in a credit line to the material. If material is not included in the article's Creative Commons licence and your intended use is not permitted by statutory regulation or exceeds the permitted use, you will need to obtain permission directly from the copyright holder. To view a copy of this licence, visit http://creativecommons.org/licenses/by/4.0/.

\section{References}

Abe K, Nakatsubo F, Yano H (2009) High-strength nanocomposite based on fibrillated chemi-thermomechanical pulp. Compos Sci Technol 69:2434-2437. https://doi.org/10. 1016/j.compscitech.2009.06.015

Ahola S, Salmi J, Johansson L-S et al (2008) Model films from native cellulose nanofibrils. Preparation, swelling, and surface interactions. Biomacromolecules 9:1273-1282. https://doi.org/10.1021/bm701317k

Ämmälä A, Laitinen O, Sirviö JA, Liimatainen H (2019) Key role of mild sulfonation of pine sawdust in the production of lignin containing microfibrillated cellulose by ultrafine wet grinding. Ind Crops Prod 140:111664. https://doi.org/ 10.1016/j.indcrop.2019.111664

Annergren GE, Rydholm SA (1959) On the behaviour of hemicelluloses during sulfite pulping. Sven Papperstidning 62:737-746

Annergren GE, Rydholm SA (1960) On the stabilization of glucomannan in the pulping processes. Sven Papperstidning 63:591-600

Besbes I, Vilar MR, Boufi S (2011) Nanofibrillated cellulose from Alfa, Eucalyptus and Pine fibres: Preparation, characteristics and reinforcing potential. Carbohydr Polym 86:1198-1206. https://doi.org/10.1016/j.carbpol.2011.06. 015

Bhardwaj NK, Duong TD, Nguyen KL (2004) Pulp charge determination by different methods: effect of beating/refining. Colloids Surf A Physicochem Eng Asp 236:39-44. https://doi.org/10.1016/j.colsurfa.2004.01.024

Brodin FW, Eriksen $\varnothing$ (2015) Preparation of individualised lignocellulose microfibrils based on thermomechanical pulp and their effect on paper properties. Nord Pulp Pap Res J 30:443-451. https://doi.org/10.3183/npprj-2015-3003-p443-451

Chaker A, Alila S, Mutjé P et al (2013) Key role of the hemicellulose content and the cell morphology on the nanofibrillation effectiveness of cellulose pulps. Cellulose 
20:2863-2875. https://doi.org/10.1007/s10570-013-0036$\mathrm{y}$

Dimic-Misic K, Puisto A, Gane P et al (2013) The role of MFC/ NFC swelling in the rheological behavior and dewatering of high consistency furnishes. Cellulose 20:2847-2861. https://doi.org/10.1007/s10570-013-0076-3

Dizhbite T, Telysheva G, Jurkjane V, Viesturs U (2004) Characterization of the radical scavenging activity of lignins natural antioxidants. Bioresour Technol 95:309-317. https://doi.org/10.1016/j.biortech.2004.02.024

Fall AB, Lindström SB, Sundman O et al (2011) Colloidal stability of aqueous nanofibrillated cellulose dispersions. Langmuir 27:11332-11338. https://doi.org/10.1021/ la201947x

Fält S, Wågberg L, Vesterlind EL (2003) Swelling of model films of cellulose having different charge densities and comparison to the swelling behavior of corresponding fibers. Langmuir 19:7895-7903. https://doi.org/10.1021/ la026984i

Fardim P, Holmbom B, Ivaska A, Karhu J (2002) Critical comparison and validation of methods for determination of anionic groups in pulp fibres. Nord Pulp Pap Res $\mathbf{J}$ 17:346-351. https://doi.org/10.3183/npprj-2002-17-03p346-351

Ferrer A, Quintana E, Filpponen I et al (2012) Effect of residual lignin and heteropolysaccharides in nanofibrillar cellulose and nanopaper from wood fibers. Cellulose 19:2179-2193. https://doi.org/10.1007/s10570-012-9788-z

Figueiredo P, Lintinen K, Hirvonen JT et al (2018) Properties and chemical modifications of lignin: Towards ligninbased nanomaterials for biomedical applications. Prog Mater Sci 93:233-269. https://doi.org/10.1016/j.pmatsci. 2017.12.001

Hanhikoski S, Warsta E, Varhimo A, Vuorinen T (2016) Sodium sulphite pulping of Scots pine under neutral and mildly alkaline conditions (NS pulping). Holzforschung 70:603-609. https://doi.org/10.1515/hf-2015-0099

Hanhikoski S, Niemelä K, Vuorinen T (2019) Biorefining of Scots pine using neutral sodium sulphite pulping: investigation of fibre and spent liquor compositions. Ind Crops Prod 129:135-141. https://doi.org/10.1016/j.indcrop.2018. 11.060

Henriksson M, Henriksson G, Berglund LA, Lindström T (2007) An environmentally friendly method for enzyme-assisted preparation of microfibrillated cellulose (MFC) nanofibers. Eur Polym J 43:3434-3441. https://doi.org/10.1016/j. eurpolymj.2007.05.038

Herrera M, Thitiwutthisakul K, Yang X et al (2018) Preparation and evaluation of high-lignin content cellulose nanofibrils from eucalyptus pulp. Cellulose 25:3121-3133. https://doi. org/10.1007/s10570-018-1764-9

Hoeger IC, Nair SS, Ragauskas AJ et al (2013) Mechanical deconstruction of lignocellulose cell walls and their enzymatic saccharification. Cellulose 20:807-818. https:// doi.org/10.1007/s10570-013-9867-9

Hoeger I, Gleisner R, Negrón J et al (2014) Mountain pine beetle-killed lodgepole pine for the production of submicron lignocellulose fibrils. For Sci 60:502-511. https://doi. org/10.5849/forsci.13-012

Horvath AE, Lindström T, Laine J (2006) On the indirect polyelectrolyte titration of cellulosic fibers. Conditions for charge stoichiometry and comparison with ESCA. Langmuir 22:824-830. https://doi.org/10.1021/la052217i

Iwamoto S, Abe K, Yano H (2008) The effect of hemicelluloses on wood pulp nanofibrillation and nanofiber network characteristics. Biomacromol 9:1022-1026. https://doi. org/10.1021/bm701157n

Janson J (1970) Calculation of the polysaccharide composition of wood and pulp. Pap Ja Puu 52:323-326

Junka K, Filpponen I, Lindström T, Laine J (2013) Titrimetric methods for the determination of surface and total charge of functionalized nanofibrillated/microfibrillated cellulose (NFC/MFC). Cellulose 20:2887-2895. https://doi.org/10. 1007/s10570-013-0043-Z

Lahtinen P, Liukkonen S, Pere J et al (2014) A comparative study of fibrillated fibers from different mechanical and chemical pulps. Bioresources 9:2115-2127. https://doi. org/10.15376/biores.9.2.2115-2127

Lindgren J, Öhman L-O, Gunnars S, Wågberg L (1994) Charge determinations of cellulose fibres of different origin Comparison between different methods. Nord Pulp Pap Res J 17:89-96. https://doi.org/10.3183/npprj-2002-17-01p089-096

Morais de Carvalho D, Moser C, Lindström ME, Sevastyanova O (2019) Impact of the chemical composition of cellulosic materials on the nanofibrillation process and nanopaper properties. Ind Crops Prod 127:203-211. https://doi.org/ 10.1016/j.indcrop.2018.10.052

Nechyporchuk O, Belgacem MN, Bras J (2016) Production of cellulose nanofibrils: a review of recent advances. Ind Crops Prod 93:2-25. https://doi.org/10.1016/j.indcrop. 2016.02.016

Ölander K, Salmén L, Htun M (1989) Relation between mechanical properties of pulp fibres and the activation energy of softening as affected by sulfonation. Nord Pulp Pap Res J 5:60-64. https://doi.org/10.3183/npprj-1990-0502-p060-064

Östberg G, Salmen L (1988) Effects of sulfonation on properties of different cell wall layers. Nord Pulp Pap Res J 3:8-12. https://doi.org/10.3183/NPPRJ-1988-03-01-p008-012

Österberg M, Vartiainen J, Lucenius J et al (2013) A fast method to produce strong NFC films as a platform for barrier and functional materials. ACS Appl Mater Interfaces 5:4640-4647. https://doi.org/10.1021/am401046x

Pääkkö M, Ankerfors M, Kosonen H et al (2007) Enzymatic hydrolysis combined with mechanical shearing and highpressure homogenization for nanoscale cellulose fibrils and strong gels. Biomacromolecules 8:1934-1941. https://doi. org/10.1021/bm061215p

Paananen M, Liitiä T, Sixta H (2013) Further insight into carbohydrate degradation and dissolution behavior during kraft cooking under elevated alkalinity without and in the presence of anthraquinone. Ind Eng Chem Res 52:12777-12784. https://doi.org/10.1021/ie4018012

Pönni R, Vuorinen T, Kontturi E (2012) Proposed nano-scale coalescence of cellulose in chemical pulp fibers during technical treatments. Bioresources 7:6077-6108. https:// doi.org/10.15376/biores.7.4.6077-6108

Rantanen J, Dimic-Misic K, Kuusisto J, Maloney TC (2015) The effect of micro and nanofibrillated cellulose water uptake on high filler content composite paper properties and 
furnish dewatering. Cellulose 22:4003-4015. https://doi. org/10.1007/s10570-015-0777-x

Rojo E, Peresin MS, Sampson WW et al (2015) Comprehensive elucidation of the effect of residual lignin on the physical, barrier, mechanical and surface properties of nanocellulose films. Green Chem 17:1853-1866. https://doi.org/10.1039/ C4GC02398F

Saito T, Nishiyama Y, Putaux JL et al (2006) Homogeneous suspensions of individualized microfibrils from TEMPOcatalyzed oxidation of native cellulose. Biomacromolecules 7:1687-1691. https://doi.org/10.1021/ bm060154s

Saito T, Kimura S, Nishiyama Y, Isogai A (2007) Cellulose nanofibers prepared by TEMPO-mediated oxidation of native cellulose. Biomacromolecules 8:2485-2491. https:// doi.org/10.1021/bm0703970

Sandas SE, Salminen PJ, Eklund DE (1989) Measuring the water retention of coating colors. Tappi J 72:207-210

Sjöström E (1977) The behavior of wood polysaccharides during alkaline pulping processes. Tappi 60:151-154

Sjöström E (1989) The origin of charge on cellulosic fibers. Nord Pulp Pap Res J 4:90-93. https://doi.org/10.3183/ npprj-1989-04-02-p090-093

Solala I, Volperts A, Andersone A et al (2012) Mechanoradical formation and its effects on birch kraft pulp during the preparation of nanofibrillated cellulose with Masuko refining. Holzforschung 66:477-483. https://doi.org/10. 1515/HF.2011.183

Solala I, Iglesias MC, Peresin MS (2020) On the potential of lignin-containing cellulose nanofibrils (LCNFs): a review on properties and applications. Cellulose 27:1853-1877. https://doi.org/10.1007/s10570-019-02899-8

Spence KL, Venditti RA, Habibi Y et al (2010a) The effect of chemical composition on microfibrillar cellulose films from wood pulps: Mechanical processing and physical properties. Bioresour Technol 101:5961-5968. https://doi. org/10.1016/j.biortech.2010.02.104

Spence KL, Venditti RA, Rojas OJ et al (2010b) The effect of chemical composition on microfibrillar cellulose films from wood pulps: Water interactions and physical properties for packaging applications. Cellulose 17:835-848. https://doi.org/10.1007/s10570-010-9424-8

Spence KL, Venditti RA, Rojas OJ et al (2011) A comparative study of energy consumption and physical properties of microfibrillated cellulose produced by different processing methods. Cellulose 18:1097-1111. https://doi.org/10. 1007/s10570-011-9533-z

Swerin A, Odberg L, Lindström T (1990) Deswelling of hardwood kraft pulp fibers by cationic polymers: The effect on wet pressing and sheet properties. Nord Pulp Pap Res J 5:188-196. https://doi.org/10.3183/npprj-1990-05-04p188-196

Tenhunen T, Soledad M, Penttilä PA et al (2014) Significance of xylan on the stability and water interactions of cellulosic nanofibrils. React Funct Polym 85:157-166. https://doi. org/10.1016/j.reactfunctpolym.2014.08.011

Visanko M, Sirviö JA, Piltonen P et al (2017) Mechanical fabrication of high-strength and redispersible wood nanofibers from unbleached groundwood pulp. Cellulose 24:4173-4187. https://doi.org/10.1007/s10570-017-14067

Wågberg L, Decher G, Norgren M et al (2008) The build-up of polyelectrolyte multilayers of microfibrillated cellulose and cationic polyelectrolytes. Langmuir 24:784-795. https://doi.org/10.1021/la702481v

Yousefi H, Azari V, Khazaeian A (2018) Direct mechanical production of wood nanofibers from raw wood microparticles with no chemical treatment. Ind Crops Prod 115:26-31. https://doi.org/10.1016/j.indcrop.2018.02.020

Zhang Y, Sjögren B, Engtrand P, Htum M (1994) Determination of charged groups in mechanical pulp fibres and their influence on pulp properties. J Wood Chem Technol 14:83-102. https://doi.org/10.1080/02773819408003087

Publisher's Note Springer Nature remains neutral with regard to jurisdictional claims in published maps and institutional affiliations. 